\title{
19 Can Fruit and Vegetable Consumption Oppose the Negative Health Effects of Tobacco?
}

\author{
Eliane Kellen and Geertruida E. Bekkering
}

\section{CONTENTS}

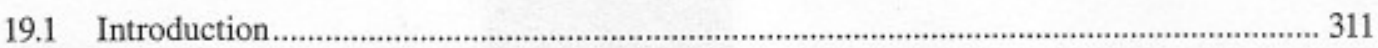

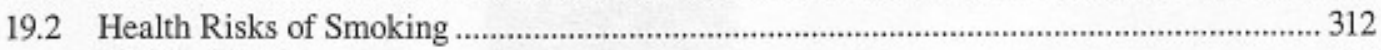

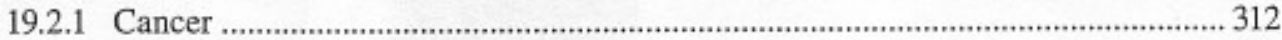

19.2.2 Cardiovascular Disease ............................................................................. 312

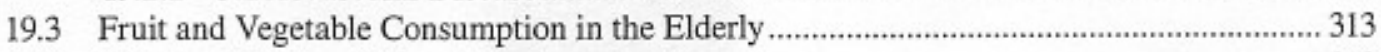

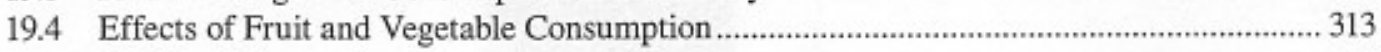

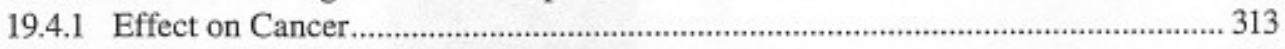

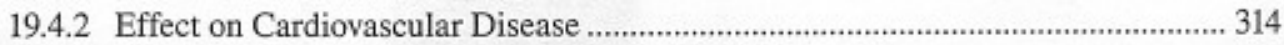

19.5 Interaction between fruit and vegetable consumption and smoking.................................. 314

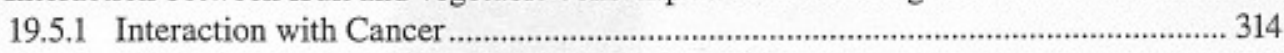

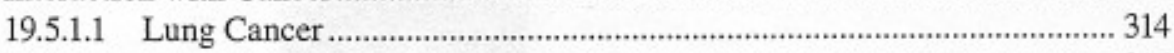

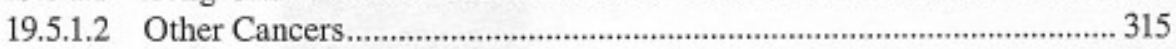

19.5.1.3 Cardiovascular Disease ....................................................................... 315

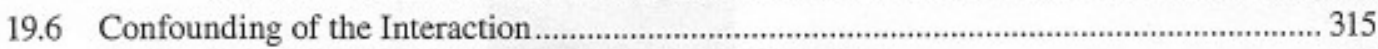

19.6.1 Assessment of Fruit and Vegetable Consumption.................................................315

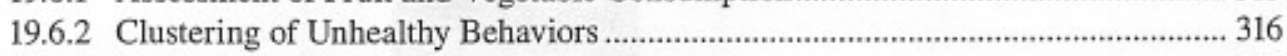

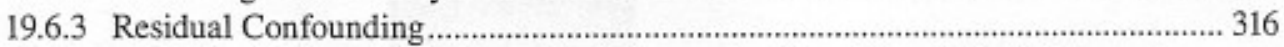

19.7 Biochemical Plausibility of the Interaction Between Fruit and Vegetable Intake and

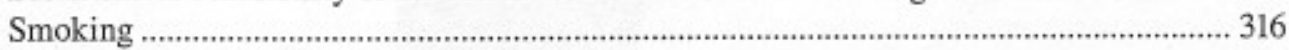

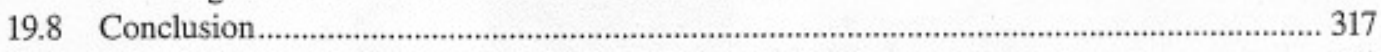

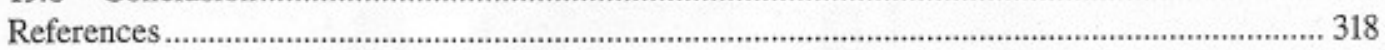

\subsection{INTRODUCTION}

Aging is associated with an increased risk of chronic diseases such as cancer and CVD. Smoking increases the risk of such diseases further. The intake of fruit and vegetables is often promoted as part of a healthy lifestyle to prevent chronic diseases. In this chapter we will discuss the health effect of smoking on cancer and CVD, describe the association between fruit and vegetable consumption and these diseases and review whether the negative health effects of smoking can be countered by fruit and vegetable consumption. Our review will focus on studies in the elderly where possible. Studies that reported on nutrients such as antioxidants were not taken into consideration. 
Tobacco* contributes to the world's leading killer diseases. If current trends continue, it will kill 100 million people prematurely during this century [1]. According to the Centers for Disease Control and Prevention's Behavioral Risk Factor Surveillance System (BRFSS), an estimated 10\% of Americans 65 and older smoked daily in the year 2002 [2].

\subsection{HEALTH RISKS OF SMOKING}

\subsubsection{CANCER}

Tobacco is a potent multisite carcinogen, causing cancers of the lung, upper aero-digestive tract, pancreas, stomach, liver, lower urinary tract, kidney and uterine cervix, and causing myeloid leukemia [3]. Smoking is estimated to cause $21 \%$ of deaths from cancer worldwide, which indicates that it is a very important preventable cause of cancer mortality. It was calculated that $70 \%$ of trachea, bronchus, and lung cancer mortality worldwide is caused by smoking; while smoking accounts for $42 \%$ of mouth and oropharynx cancer mortality, $42 \%$ of oesophageal cancer mortality, $22 \%$ of pancreatic cancer mortality, $28 \%$ of bladder cancer mortality and $14 \%$ of liver cancer mortality [4]. Evidence of a positive relationship between involuntary passive second-hand smoking, or environmental tobacco smoke and lung cancer in nonsmokers is increasing. This association is biologically plausible, as passive smokers inhale the same carcinogens as active smokers, albeit at a lower dose [5].

Cigarette smoke contains a mixture of more than 60 carcinogens, most of which require metabolic activation to impose their carcinogenic effect; there are competing detoxification pathways. The balance between metabolic activation and detoxification differs among individuals and affects their cancer susceptibility. Persons with higher carcinogen activation and lower detoxification capacity have the highest risk of developing cancer. Metabolic activation of carcinogens leads to the formation of DNA adducts. A DNA adduct is formed when carcinogen metabolites bind to DNA. DNA adducts are absolutely central to the carcinogenic process. If their formation is inhibited or blocked, so is the carcinogenesis. If DNA adducts escape cellular repair mechanisms and persist, they may lead to miscoding, persisting in permanent mutations. Cells with damaged DNA may be removed by apoptosis or programmed cell death. If a permanent mutation occurs in a critical region of an oncogene (genes that stimulate cell division) or tumor suppressor gene (genes that prevent cell division), it can lead to activation of the oncogene or deactivation of the tumor suppressor gene. Multiple events of this type may lead to cells that have lost normal growth control mechanisms and eventually become cancer [6,7]. Furthermore, smoking may impair the immune system, further increasing the risk of cancer [8].

\subsubsection{Cardiovascular Disease}

Tobacco use is an important cause of acute myocardial infarction worldwide, especially in men [9]. It has been estimated that more than one in every 10 cardiovascular deaths in the world in the year 2000 were attributable to smoking [10]. Quitting smoking will reduce all-cause mortality by $36 \%$ among patients with coronary heart disease CHD. [11]. Smoking increases the risk for both ischemic and hemorrhagic stroke and contributes to $12 \%$ to $14 \%$ of all stroke deaths [12].

Epidemiological evidence indicates a positive association between passive or secondhand smoking and the incidence of CVD [13]. This suggests that even very low levels of cigarette smoke increases the risk. Exposure to environmental tobacco smoke causes a $25 \%$ increase in risk of ischemic heart disease. This large effect of such a small exposure is mainly explained by a nonlinear dose-response relation between exposure and risk of heart disease [14]. It has been shown that

"In this chapter the terms "tobacco" and "smoking" refer to all forms of tobacco smoking: smoking of cigarettes, pipes, cigars, or bidis which contain tobacco wrapped in the leaf of another plant. 
passive smokers have disproportionately increased levels of fibrinogen and homocysteine which are two biomarkers of CVD risk. [15]. Nicotine, and its major metabolites cotinine, carbon monoxide, and thiocyanate are the main biochemical factors responsible for cardiovascular harm [16].

Cigarette smoking impacts all phases of atherosclerosis from endothelial dysfunction to acute clinical events, which are largely thrombotic. Vasomotor dysfunction or impairment of the vasodilatory function, inflammation which is an essential phase, and modification of the lipid profile are components of initiation and progression of artherosclerosis. These three phases precede clinical events. Furthermore, cigarette smoke is associated with dysfunctional thrombohemostatic mechanisms (platelet dysfunction, alteration of antithrombotic and prothrombotic factors, and alteration in fibrinolysis) that promote the initiation and progression of thrombus formation and limit its effective dissolution [17].

Most of the dysfunctions described above can be explained by oxidative stress, which is a consequence of smoking [17]. The anatomical and ultrastructural cardiovascular changes due to smoking are named "smoke cardiomyopathy" [16].

\subsection{FRUIT AND VEGETABLE CONSUMPTION IN THE ELDERLY}

The intake of fruit and vegetables is often lower than the recommended five or more servings daily. Only $33.3 \% \pm 4.9 \%$ of the female U.S. population older than 70 met that recommendation in 1999-2000; for the male population older than 70 , this was $55.9 \% \pm 4.4 \%$ [18].

\subsection{EFFECTS OF FRUIT AND VEGETABLE CONSUMPTION}

A diet of at least 400 grams per day of total fruit and vegetables. has often been promoted as reducing chronic disease risk. However, the epidemiological evidence is not as convincing as was anticipated. In general, cohort studies provide weaker evidence than do case control studies [19]. The differences in result may be partly explained by bias. Retrospective studies are more prone to several types of biases, which may lead to an overestimation of the association, such as (recall bias recall of diet is biased by the diagnosis), selection bias (controls who are willing to participate may be health conscious and thus consuming more fruits and vegetables than those who are not) and bias due to the change of diet and lifestyle following CVD events or being diagnosed with cancer.

\subsubsection{EFFect on CANCER}

The consumption of fruit and vegetables probably decreases the risk of several cancers. This was the conclusion of the largest project ever to investigate the association between diet and cancer, performed by the World Cancer Research Fund (WCRF) and the American Institute for Cancer Research (AICR) [20]. All available evidence was accumulated in one report that concluded that the intake of fruits as well as vegetables decreases the risk of cancers of mouth, pharynx, larynx, esophagus, and stomach. In addition, fruit also reduced the risk of lung cancer. The strength of association was labeled probable, which means there is still uncertainty in the causal relationship. In addition, a suggestive protective association was found between vegetables and cancers of the nasopharynx, lung, colorectum, ovary, and endometrium and between fruit and cancers of the nasopharynx, pancreas, liver, and colorectum.

Based on this report, the WCRF and AICR recommends everybody to consume at least five portions/servings (at least $400 \mathrm{~g}$ or $14 \mathrm{oz}$ ) of a variety of nonstarchy vegetables and fruits every day [20]. 


\subsubsection{Effect on Cardiovascular Disease}

Fruit and vegetable consumption seems to be inversely associated with the occurrence of $\mathrm{CHD}$ $[19,21]$ and with a reduced risk of stroke [22]. A high daily consumption (400-500 grams) of fresh fruit and vegetables is recommended to reduce the risk of $\mathrm{CHD}$, stroke, and high blood pressure [23]. Few studies have focused on the elderly. A study among 3588 men and women aged 65 years or older found no association between fruit and vegetable fiber intake and incident CVD [24]. In contrast, a study among 1299 elderly Massachusetts residents found that residents consuming more carotene-containing fruits and vegetables had lower risk of cardiovascular mortality and myocardial infarction [25]. The global mortality attributable to inadequate consumption of fruit and vegetables was estimated to be up to 2.635 million deaths per year [26]. Increasing individual fruit and vegetable consumption to up to $600 \mathrm{~g}$ per day could reduce the burden of ischemic heart disease by $31 \%$ and ischemic stroke by $19 \%$.

Although no trials have assessed the intake of fruit and vegetables on primary prevention of $\mathrm{CHD}$, there is some evidence on secondary prevention. Ornish et al. 1998. investigated the effect of intensive lifestyle changes in patients with moderate to severe CHD [27]. Lifestyle changes consisted of $10 \%$ fat whole foods, a vegetarian diet, aerobic exercise, stress management training, smoking cessation, and psychological support for 5 years. The authors concluded that more regression of coronary atherosclerosis occurred after 5 years than after 1 year in the experimental group. In contrast, in the control group, coronary atherosclerosis continued to progress and more than twice as many cardiac events occurred.

\subsection{INTERACTION BETWEEN FRUIT AND VEGETABLE CONSUMPTION AND SMOKING}

Chronic diseases are likely to be caused by a combination of environmental factors, genes, and their interaction. For example, only $15 \%$ of lifelong smokers in the Western world will develop lung cancer before the age of 75 [28]. This suggests that other factors than smoking alone affect the risk of developing lung cancer.

This section reviews the interaction between fruit and vegetable consumption and smoking. For example, is the protective effect of fruit and vegetables different for smokers than for nonsmokers? Are the antioxidant mechanisms found in fruit and vegetables more important in the presence of high levels of oxidizing DNA-damaging free radicals smoking [29]? And, is the detrimental effect of smoking different for persons who eat more than the recommended five daily servings of vegetables and fruits compared with those who eat less?

\subsubsection{InTERACTION With Cancer}

Tobacco-specific nitrosamines and polycyclic aromatic hydrocarbons undergo activation and detoxification processes that are controlled by antioxidants such as quercetin in vegetables and sulforaphane in broccoli [30].

\subsubsection{Lung Cancer}

Several studies assessed the effect of fruit and vegetables in smokers and nonsmokers, but the results on a possible interaction are equivocal. A case-control study found a protective effect of vegetables and apples on lung cancer risk among smokers, but not among nonsmokers [31]. Another case-control study found a fivefold increased risk in lung cancer for smokers reporting a low consumption compared with never smokers reporting high intake of fruit and vegetables, [32]. A large prospective cohort found that lung cancer incidence was lower in smokers with high vegetable intake than in those with a low intake [33]. In contrast, a Swedish case-control study found a protective effect of vegetable consumption on lung cancer risk among both nonsmokers and smokers including former 
smokers. [34]. Based on a pooled analysis of eight prospective studies, it was suggested that risk of lung cancer in never smokers with high consumption of fruit is decreased by $41 \%$ compared with those consuming less fruit. However, this association was not significant. Weaker associations were observed among current and past smokers, while vegetable consumption was negatively associated with lung cancer risk only among current smokers [35].

\subsubsection{Other Cancers}

The risks estimated of tobacco use on the occurrence of gastric cancer seems to be higher among those with low fruit consumption than among frequent fruit-eaters [36]. The protective effects of carotenoids on bladder cancer risk has been found to be confined largely to ever-smokers and were stronger in current than ex-smokers [37]. A case control study suggested that by increasing the daily fruit consumption, the risk of ever-smokers for developing bladder cancer decreased; however it still remained significant [38]. Even in the presence of heavy smoking, a high fruit and vegetable consumption is protective for the risk of head and neck cancer. Forty percent of the cases among ever-smokers appears to be related to the interaction of both risk factors [39].

However, a pooled analysis of two prospective cohort studies found no association between fruit and vegetable consumption and overall cancer risk among never, past, or current smokers except for cruciferous vegetables among male current smokers [40].

A randomized trial investigated the ability of dietary changes in particular diets rich in cruciferous vegetables and flavanoids to increase urinary antimutagenicity and inhibit DNA damage in healthy male smokers at least 15 cigarettes/day for the last 10 years. The data suggested that adherence to a diet rich in cruciferous vegetables and flavanoids was associated with a decrease in adducts after 1 year. However, the authors conclude that smoking is the most important single preventable cause of cancer and that it is unlikely that dietary habits can substantially counteract its effects [41].

\subsubsection{Cardiovascular Disease}

Interaction between fruit and vegetable consumption and smoking for CVD is sparsely examined. To the best of our knowledge, no epidemiological studies assessed whether the effect of smoking on CVD was modified by fruit and vegetable intake. In contrast, several cohort studies assessed whether the effect of fruit and vegetable intake on CVD was modified by smoking. Two cohort studies and a pooled analyses based on two other cohort studies suggested that the protective association was more apparent in current smokers $[40,42,43]$, although the evidence on interaction was weak, if presented. Another cohort observed no clear interaction between smoking and fruit intake [44].

\subsection{CONFOUNDING OF THE INTERACTION}

As stated above, cohort studies typically provide weaker evidence on the association of fruit and vegetables with chronic disease than do retrospective studies. In addition, results of observational studies may not be confirmed in clinical trials. This has, for example, been shown the relationship between $\beta$-carotene and lung cancer. Observational studies showed a protective effect of carotenoids on lung cancer, especially in smokers [46]. However, randomized controlled studies failed to demonstrate reduced lung cancer incidence after prolonged $\beta$-carotene supplementation, and even suggested the possibility of harm $[47,48]$. Bias may partly explain why an effect found in observational studies is not apparent in randomized clinical trials.

\subsubsection{Assessment of Fruit and Vegetable Consumption}

The consumption of fruit and vegetable is difficult to measure. Estimates of fruit and vegetable intake and disease associations may differ depending on the method used to assess fruit and 
vegetable intake [49]. For example, food frequency questionnaire-based measures of fruit and vegetable intake have limitations, primarily due to their imprecise assessment of vegetable intake [50]. Also, the majority of observational studies, even cohort studies, note a dietary assessment only at baseline. Any changes to the diet will, therefore, not be taken into account, which may bias the estimate of association.

\subsubsection{Clustering of Unhealthy Behaviors}

Consumption of fruit and vegetables is typically connected with behavior that is associated with a reduction of cardiovascular and cancer risk. For example, individuals who eat more fruit and vegetables are likely to have lower rates of smoking, a lower intake of salt and saturated fat, higher levels of physical activity, and are less likely to be overweight [44]. Such a clustering of healthy behavior was reported in a European study with subjects aged 60 years or more [51]. Smokers commonly have higher intakes of energy, total fat, saturated fat, cholesterol, and alcohol, and lower intakes of unsaturated fat, fiber, vitamin $\mathrm{C}$, vitamin $\mathrm{E}$, and $\beta$-carotene than nonsmokers [52]. Thus, smokers typically have dietary patterns that further exacerbate their smoking-related risk of cancer and CVD, making it difficult to estimate the effect of a single food or nutrient.

\subsubsection{Residual Confounding}

Inadequate control of confounding may lead to an overestimation of the protective effect of fruit and vegetable consumption in smokers. Especially relevant in this respect is residual confounding, which refers to confounding due to measurement error in a known confounder that is included in a model [53]. This could, for example, arise when results are adjusted for smoking status yes versus no. instead of pack-years, but also when self-reported smoking status is used instead of a biomarker. The risk on residual confounding is especially great when investigating a disease with a very strong risk factor such as lung cancer and smoking. that is inversely associated with the exposure of interest such as fruit and vegetable consumption. or when the exposure of interest is weak compared with the confounder [54]. A simulation study suggested that biases in assessment of smoking exposure between smokers with low versus high $\beta$-carotene intake, leading to residual confounding, may plausibly explain much of the observed protective effect of $\beta$-carotene levels seen in epidemiological studies [55]. Carefully controlling for residual confounding is indicated in observational studies. After stepwise adjustment for smoking status, duration of smoking, and amount of cigarettes per day, a cohort study found that the negative associations between fruit and vegetable consumption and lung cancer attenuated and remained significant only for people in the highest quartile of vegetable consumption [54].

\subsection{BIOCHEMICAL PLAUSIBILITY OF THE INTERACTION BETWEEN FRUIT AND VEGETABLE INTAKE AND SMOKING}

Smoking induces oxidative stress. One "puff" exposes the smoker to more than $10^{15}$ free radicals and additional free radicals and oxidants are found in the tar [56]. Antioxidants are the best protectors of the damage caused by oxidative stress. Two of best-documented categories are the carotenoids and the bioflavonoids. The carotenoids can be found in highly colored fruit and vegetables such as carrots, tomatoes, peppers, and grapefruit. Flavonoids are found in a wide variety of foods-not necessarily colored-such as grapes, cherries, and tea [57]. As mentioned above, clinical trials showed no association between carotene supplements and cancer risk. It has been argued that the complex mixture of micronutrients found in a diet high in fruit and vegetables may be more effective than large supplemental doses of a small number of micronutrients [58]. Future clinical trials should therefore focus on dietary patterns and not on specific vitamins or even food items. 
It has been shown that blood concentrations of antioxidants are lower in smokers than in nonsmokers. This difference remains after adjustments for dietary differences. It is suggested that this relates to the inflammatory changes due to smoking that are associated with an increased turnover of vitamin $\mathrm{C}$ and carotenoid-containing foods [56]. Furthermore, chronic smoking leads to depletion of trace elements such as selenium or zinc, and by interference with the transcription of redoxrelevant enzymes. This followed by an up regulation of antioxidative enzymes and factors e.g., gluthathione. After years of smoking, metal catalysts for oxidation reaction accumulate in the vessel wall, and accelerate oxidation reactions, which finally lead to a permanent oxidative deterioration of the cardiovascular system [59]. It is recommended that supplements of trace elements and metal chelating and detoxifying agents should be added to antioxidant supplementation in order to reduce CVD in chronic smokers [59].

Low penetrant genetic conditions may be involved in processes related to diet and smoking. These conditions strongly influence the individual biologic response to environmental carcinogens, which results in a lower or higher susceptibility for certain diseases. In such cases, it can be reasoned that the protective effect of fruit and vegetables, which are important sources of antioxidants, depends on a person's genotype in addition to the amount of oxidative stress. Oxidative stress is a consequence of cigarette smoking. Genetic polymorphisms leading to fast metabolization of smoking carcinogens could lead to less DNA damage from oxidative stress. Hence, the protective effect of the dietary antioxidants may be less in persons of the genotype "fast metabolization." Thus, some subgroups defined by genotype and phenotype may benefit more from dietary strategies. The protective effect of cruciferous vegetable consumption on the risk of myocardial infarction among persons with the $G S T T I^{*} l$ allele was greater for current smokers than for non-smokers genetic polymorphism $\mathrm{x}$ diet $\mathrm{x}$ smoking interaction. It seems that persons with an low functioning GSTTI allele may benefit more from the protective effects of cruciferous vegetables than those with higheractivity genotype because the isothiocyanates could remain in the body longer [45]. The field of gene-nutrient interactions is currently under development.

\subsection{CONCLUSION}

Smoking increases the risk of chronic diseases such as cancer and CVD. The intake of fruits and vegetables seems to have a modest protective effect on the occurrence of these diseases. However, this has been investigated only in observational studies and bias may partly explain the protective association found.

The consumption of fruit and vegetables seems to have a beneficial effect on some cancer risk in smokers. Such an association was weaker, if present, in CVD. To date, no long-term intervention study has determined that increasing fruit and vegetable intake resulted in a decrease in heart disease and cancer incidence and mortality among smokers [60].

The importance of smoking cessation, even at an older age, has been demonstrated. Adhering to a healthy lifestyle in middle age has been shown to lead to a reduction in CVD risk and mortality [61]. Up to $92 \%$ of the myocardial infarctions in postmenopausal women may be prevented by consuming a healthy diet high intake of fruit and vegetables, whole grains, fish, and legumes. in combination with moderate alcohol consumption, being physically active, not smoking, and maintaining a healthy weight [62]. Persons who adhere to a Mediterranean type of diet rich in plant foods and cereals and with olive oil as an important fat source, and maintain a healthy lifestyle of nonsmoking, moderate alcohol consumption, and at least 30 minutes of physical activity per day, are less likely to die from all-cause and cause-specific mortality even at ages 70 to 90 years [63].

In conclusion, there is insufficient evidence that increased fruit and vegetable intake can be a substitute for smoking cessation. Therefore, the advice to quit smoking should remain the mainstay of a healthy lifestyle for everybody. 


\section{REFERENCES}

1. Frieden, T. R. and Bloomberg, M. R. 2007. How to prevent 100 million deaths from tobacco. Lancet $369,1758-1761$.

2. National Center for Chronic Disease Prevention and Health Promotion. Behavioral Risk Factor Surveillance System. CDC. 2007.

3. Vineis, P., Alavanja, M., Buffler, P., Fontham, E., Franceschi, S., Gao, Y. T., et al. 2004. Tobacco and cancer: Recent epidemiological evidence. J. Natl. Cancer Inst. 96, 99-106.

4. Danaei, G., Vander, H. S., Lopez, A. D., Murray, C. J. and Ezzati, M. 2005. Causes of cancer in the world: Comparative risk assessment of nine behavioural and environmental risk factors. Lancet 366 , 1784-1793.

5. Hecht, S. S. 2004. Carcinogen derived biomarkers: applications in studies of human exposure to secondhand tobacco smoke. Tob. Control 13 Suppl 1, i48-i56.

6. Hecht, S. S. 2003. Tobacco carcinogens, their biomarkers and tobacco-induced cancer. Nat. Rev. Cancer 3, 733-744.

7. Wogan, G. N., Hecht, S. S., Felton, J. S., Conney, A. H. and Loeb, L. A. 2004. Environmental and chemical carcinogenesis. Semin. Cancer Biol. 14, 473-486.

8. Sopori, M. 2002. Effects of cigarette smoke on the immune system. Nat. Rev. Immunol. 2, 372-377.

9. Teo, K. K., Ounpuu, S., Hawken, S., Pandey, M. R., Valentin, V., Hunt, D., Diaz, R., Rashed, W., Freeman, R., Jiang, L., Zhang, X. and Yusuf, S. 2006. Tobacco use and risk of myocardial infarction in 52 countries in the INTERHEART study: A case-control study. Lancet 368, 647-658.

10. Ezzati, M., Henley, S. J., Thun, M. J. and Lopez, A. D. 2005. Role of smoking in global and regional cardiovascular mortality. Circulation 112, 489-497.

11. Critchley, J. and Capewell, S. 2004. Smoking cessation for the secondary prevention of CHD. Cochrane. Database. Syst. Rev., CD003041.

12. Goldstein, L. B., Adams, R., Alberts, M. J., Appel, L. J., Brass, L. M., Bushnell, C. D., et al. 2006. Primary prevention of ischemic stroke: A guideline from the American Heart Association/American Stroke Association Stroke Council. Circulation 113, e873-e923.

13. Raupach, T., Schafer, K., Konstantinides, S., and Andreas, S. 2006. Secondhand smoke as an acute threat for the cardiovascular system: A change in paradigm. Eur. Heart J. 27, 386-392.

14. Law, M. R., Morris, J. K., and Wald, N. J. 1997. Environmental tobacco smoke exposure and ischaemic heart disease: An evaluation of the evidence. BMJ 315, 973-980.

15. Venn, A. and Britton, J. 2007. Exposure to secondhand smoke and biomarkers of cardiovascular disease risk in never-smoking adults. Circulation 115, 990-995.

16. Leone, A. 2005. Biochemical markers of cardiovascular damage from tobacco smoke. Curr. Pharm. Des. 11, 2199-2208.

17. Ambrose, J. A. and Barua, R. S. 2004. The pathophysiology of cigarette smoking and cardiovascular disease: An update. J. Am. Coll. Cardiol. 43, 1731-1737.

18. Guenther, P. M., Dodd, K. W., Reedy, J., and Krebs-Smith, S. M. 2006. Most Americans eat much less than recommended amounts of fruits and vegetables. J. Am. Diet. Assoc. 106, 1371-1379.

19. He, F. J., Nowson, C. A., Lucas, M., and MacGregor, G. A. 2007. Increased consumption of fruit and vegetables is related to a reduced risk of CHD: Meta-analysis of cohort studies. J. Hum. Hypertens. 21, 717-728.

20. World Cancer Research Fund/ American Institute for Cancer Research. Food, nutrition, physical activity, and the prevention of cancer: a global perspective. 2007. Washington DC, AICR.

21. Dauchet, L., Amouyel, P., Hercberg, S. and Dallongeville, J. 2006. Fruit and vegetable consumption and risk of CHD: A meta-analysis of cohort studies. J. Nutr. 136, 2588-2593.

22. He, F. J., Nowson, C. A. and MacGregor, G. A. 2006. Fruit and vegetable consumption and stroke: Meta-analysis of cohort studies. Lancet 367, 320-326.

23. Joint WHO/FAO expert consultation on Diet, Nutrition and the Prevention of Chronic Diseases. Diet, nutrition and the prevention of chronic diseases: report of a joint WHO/FAO expert consultation. WHO technical report series; 916. 2003. Geneva.

24. Mozaffarian, D., Kumanyika, S. K., Lemaitre, R. N., Olson, J. L., Burke, G. L., and Siscovick, D. S. 2003. Cereal, fruit, and vegetable fiber intake and the risk of CVD in elderly individuals. JAMA 289, 1659-1666. 
25. Gaziano, J. M., Manson, J. E., Branch, L. G., Colditz, G. A., Willett, W. C., and Buring, J. E. 1995. A prospective study of consumption of carotenoids in fruits and vegetables and decreased cardiovascular mortality in the elderly. Ann. Epidemiol. 5, 255-260.

26. Lock, K., Pomerleau, J., Causer, L., Altmann, D. R. and McKee, M. 2005. The global burden of disease attributable to low consumption of fruit and vegetables: Implications for the global strategy on diet. Bull. World Health Organ. 83, 100-108.

27. Ornish, D., Scherwitz, L. W., Billings, J. H., Brown, S. E., Gould, K. L., Merritt, T. A., et al. 1998. Intensive lifestyle changes for reversal of CHD. JAMA 280, 2001-2007.

28. Peto, R., Darby, S., Deo, H., Silcocks, P., Whitley, E. and Doll, R. 2000. Smoking, smoking cessation, and lung cancer in the UK since 1950: Combination of national statistics with two case-control studies. BMJ 321, 323-329.

29. Terry, P., Terry, J. B., and Wolk, A. 2001. Fruit and vegetable consumption in the prevention of cancer: An update. J. Intern. Med. 250, 280-290.

30. Weisburger, J. H. 1999. Antimutagens, anticarcinogens, and effective worldwide cancer prevention. $J$. Environ. Pathol. Toxicol. Oncol. 18, 85-93.

31. Kubik, A., Zatloukal, P., Tomasek, L., Pauk, N., Havel, L., Dolezal, J. and Plesko, L 2007. Interactions between smoking and other exposures associated with lung cancer risk in women: diet and physical activity. Neoplasma 54, 83-88.

32. Galeone, C., Negri, E., Pelucchi, C., La, V. C., Bosetti, C., and Hu, J. 2007. Dietary intake of fruit and vegetable and lung cancer risk: A case-control study in Harbin, northeast China. Ann. Oncol. 18, 388-392.

33. Linseisen, J., Rohrmann, S., Miller, A. B., Bueno-de-Mesquita, H. B., Buchner, F. L., Vineis, P., et al. 2007. Fruit and vegetable consumption and lung cancer risk: Updated information from the European Prospective Investigation into Cancer and Nutrition EPIC. Int. J. Cancer 121, 1103-1114.

34. Rylander, R. and Axelsson, G. 2006. Lung cancer risks in relation to vegetable and fruit consumption and smoking. Int. J. Cancer 118, 739-743.

35. Smith-Warner, S. A., Spiegelman, D., Yaun, S. S., Albanes, D., Beeson, W. L., van den Brandt, P. A., et al. 2003. Fruits, vegetables and lung cancer: A pooled analysis of cohort studies. Int. J. Cancer 107, 1001-1011.

36. Hansson, L. E., Baron, J., Nyren, O., Bergstrom, R., Wolk, A. and Adami, H. O. 1994. Tobacco, alcohol and the risk of gastric cancer. A population-based case-control study in Sweden. Int. J. Cancer 57, 26-31.

37. Castelao, J. E., Yuan, J. M., Gago-Dominguez, M., Skipper, P. L., Tannenbaum, S. R., Chan, K. K., et al. 2004. Carotenoids/vitamin C and smoking-related bladder cancer. Int. J. Cancer 110, 417-423.

38. Kellen, E., Zeegers, M., Paulussen, A., Van, D. M., and Buntinx, F. 2006. Fruit consumption reduces the effect of smoking on bladder cancer risk. The Belgian case control study on bladder cancer. Int. J. Cancer 118, 2572-2578.

39. Boccia, S., Cadoni, G., Sayed-Tabatabaei, F. A., Volante, M., Arzani, D., De Lauretis, A., et al. 2008. CYPIA1, CYP2E1, GSTM1, GSTT1, EPHX1 exons 3 and 4, and NAT2 polymorphisms, smoking, consumption of alcohol and fruit and vegetables and risk of head and neck cancer. J. Cancer Res. Clin. Oncol. 134, 93-100.

40. Hung, H. C., Joshipura, K. J., Jiang, R., Hu, F. B., Hunter, D., Smith-Warner, S. A., et al. 2004. Fruit and vegetable intake and risk of major chronic disease. J. Natl. Cancer Inst., 96, 1577-1584.

41. Talaska, G., Al-Zoughool, M., Malaveille, C., Fiorini, L., Schumann, B., Vietas, J., et al. 2006. Randomized controlled trial: Effects of diet on DNA damage in heavy smokers. Mutagenesis 21, 179-183.

42. Liu, S., Manson, J. E., Lee, I. M., Cole, S. R., Hennekens, C. H., Willett, W. C., and Buring, J. E. 2000. Fruit and vegetable intake and risk of cardiovascular disease: The Women's Health Study. Am J. Clin. Nutr. 72, 922-928.

43. Liu, S., Lee, I. M., Ajani, U., Cole, S. R., Buring, J. E., and Manson, J. E. 2001. Intake of vegetables rich in carotenoids and risk of CHD in men: The Physicians' Health Study. Int. J. Epidemiol. 30, 130-135.

44. Bazzano, L. A., He, J., Ogden, L. G., Loria, C. M., Vupputuri, S., Myers, L., and Whelton, P. K. 2002. Fruit and vegetable intake and risk of CVD in US adults: The first National Health and Nutrition Examination Survey Epidemiologic Follow-up Study. Am J. Clin. Nutr. 76, 93-99.

45. Cornelis, M. C., El-Sohemy, A., and Campos, H. 2007. GSTT1 genotype modifies the association between cruciferous vegetable intake and the risk of myocardial infarction. Am. J. Clin. Nutr. 86, $752-758$. 
46. Steinmetz, K. A. and Potter, J. D. 1991. Vegetables, fruit, and cancer. I. Epidemiology. Cancer Causes Control 2, 325-357.

47. Omenn, G. S., Goodman, G. E., Thornquist, M. D., Balmes, J., Cullen, M. R., Glass, A., et al. 1996. Effects of a combination of beta carotene and vitamin A on lung cancer and CVD. N. Engl. J. Med. 334, $1150-1155$.

48. Hennekens, C. H., Buring, J. E., Manson, J. E., Stampfer, M., Rosner, B., Cook, N. R., et al. 1996. Lack of effect of long-term supplementation with beta carotene on the incidence of malignant neoplasms and CVD. N. Engl. J. Med., 334, 1145-1149.

49. Smith-Warner, S. A., Elmer, P. J., Fosdick, L., Tharp, T. M., and Randall, B. 1997. Reliability and comparability of three dietary assessment methods for estimating fruit and vegetable intakes. Epidemiology 8, 196-201.

50. Kristal, A. R., Vizenor, N. C., Patterson, R. E., Neuhouser, M. L., Shattuck, A. L., and McLerran, D. 2000. Precision and bias of food frequency-based measures of fruit and vegetable intakes. Cancer Epidemiol, Biomarkers Prev. 9, 939-944.

51. Bamia, C., Orfanos, P., Ferrari, P., Overvad, K., Hundborg, H. H., Tjonneland, A., et al. 2005. Dietary patterns among older Europeans: The EPIC-Elderly study. Br. J. Nutr. 94, 100-113.

52. Dallongeville, J., Marecaux, N., Fruchart, J. C., and Amouyel, P. 1998. Cigarette smoking is associated with unhealthy patterns of nutrient intake: A meta-analysis. J. Nutr. 128, 1450-1457.

53. Fewell, Z., Davey, S. G., and Sterne, J. A. 2007. The impact of residual and unmeasured confounding in epidemiologic studies: a simulation study. Am J. Epidemiol. 166, 646-655.

54. Skuladottir, H., Tjoenneland, A., Overvad, K., Stripp, C., Christensen, J., Raaschou-Nielsen, O., and Olsen, J. H. 2004. Does insufficient adjustment for smoking explain the preventive effects of fruit and vegetables on lung cancer? Lung Cancer 45, 1-10.

55. Stram, D. O., Huberman, M., and Wu, A. H. 2002. Is residual confounding a reasonable explanation for the apparent protective effects of beta-carotene found in epidemiologic studies of lung cancer in smokers? Am. J. Epidemiol. 155, 622-628.

56. Northrop-Clewes, C. A. and Thurnham, D. I. 2007. Monitoring micronutrients in cigarette smokers. Clin. Chim. Acta 377, 14-38.

57. Furst, A. 2002. Can nutrition affect chemical toxicity? Int. J. Toxicol. 21, 419-424.

58. Woodside, J. V., McCall, D., McGartland, C., and Young, I. S. 2005. Micronutrients: dietary intake v. supplement use. Proc. Nutr. Soc. 64, 543-553.

59. Bernhard, D. and Wang, X. L. 2007. Smoking, oxidative stress and cardiovascular diseases-do antioxidative therapies fail? Curr. Med. Chem. 14, 1703-1712.

60. Kelly, G. S. 2002. The interaction of cigarette smoking and antioxidants. Part I: diet and carotenoids. Altern. Med. Rev. 7, 370-388.

61. King, D. E., Mainous, A. G., III , and Geesey, M. E. 2007. Turning back the clock: Adopting a healthy lifestyle in middle age. Am. J. Med. 120, 598-603.

62. Akesson, A., Weismayer, C., Newby, P. K., and Wolk, A. 2007. Combined effect of low-risk dietary and lifestyle behaviors in primary prevention of myocardial infarction in women. Arch. Intern. Med. 167, 2122-2127.

63. Knoops, K. T., de Groot, L. C., Kromhout, D., Perrin, A. E., Moreiras-Varela, O., Menotti, A. and van Staveren, W. A. 2004. Mediterranean diet, lifestyle factors, and 10-year mortality in elderly European men and women: The HALE project. JAMA 292, 1433-1439. 


\section{$\mathrm{HANDBOOKOF}$ Nutrition}

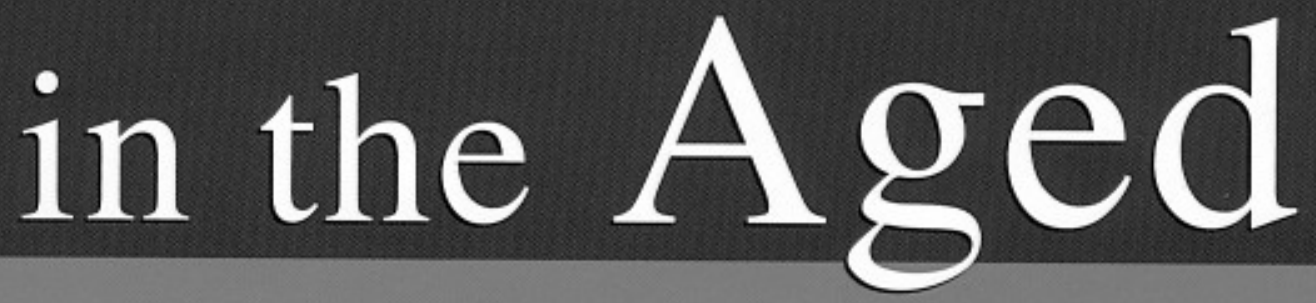

F O U R T H E D I T I O N

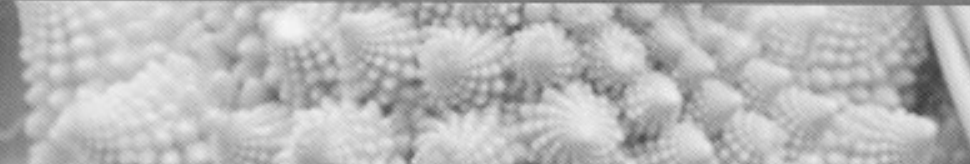

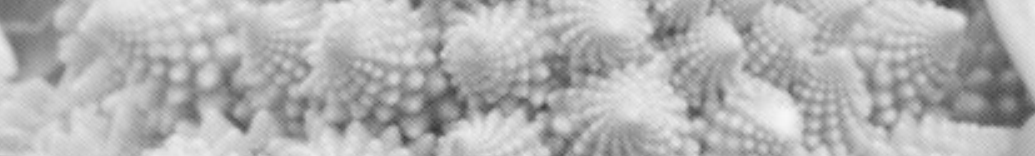
A

$4.2+3 \times 2$

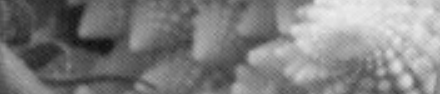

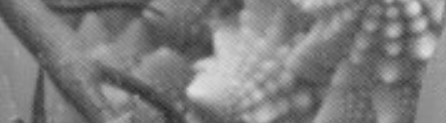

8. Ronald Ross Watson<smiles>C1CCC(C2CCC2)C1</smiles>

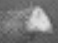

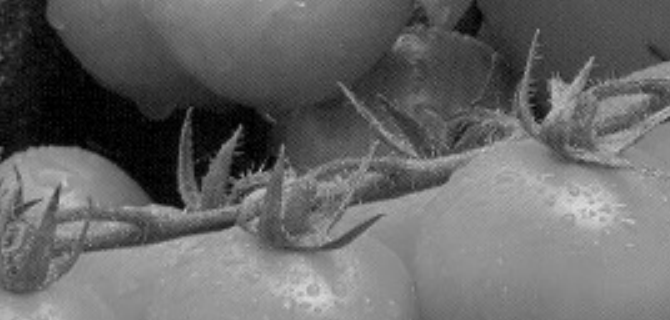


Nutrition

\section{$\mathrm{HANDBOKOF}$ Nutrition}

\section{in the \\ Aged \\ FOURTH EDITION}

The combination of the aging baby-boomer generation and its members' increased longevity has been fortunately met with increased research and greater understanding of health promotion and disease prevention in the elderly. Handbook of Nutrition in the Aged: Fourth Edition shares these groundbreaking insights and serves as a guide to better understand health problems that occur in aging adults and the nutritional therapies that are proven to fight and prevent them.

In addition to presenting nutritional therapies to overcome health problems in the aging, this fourth edition:

- Includes new sections on alcohol and beverages in health degradation and complementary and alternative medicines

- Features new chapters on arthritis, cognitive function, diabetes prevention, cancer, and protein and vitamin intake

- Provides current research on adequate diets, malnutrition, longevity, disease prevention, and nutritional supplements

This sharply focused work recognizes the special nutrition hurdles associated with the aged, particularly the decline of nutrient intake that compromises health. As a globally relevant text, this book is a valuable tool not only for geriatricians and gerontologists, but also for dietitians, nutritionists, and researchers on aging. It provides all the necessary information for assisting the growing aging population in maintaining a healthy quality of life.

\section{8}

ISBN : $978-1-4200-5973-?$ || || || || |||||||||||||

CRC Press Taylor \& Francis Group an informa business

6000 Graken Sound Parkwow, NW Sute 300, Boca Roton, F. 3348 ?

270 Madison Akenue

New York, NY 10016

2 Park Squarc, Milton Park

Abingdon, OxCn OX14 4RN, UK. 